\title{
Impact of $\mathrm{pH}$ and application time of meta-phosphoric acid on resin-enamel and resin-dentin bonding
}

\author{
A.F.M. Cardenas ${ }^{a}$, F.S.F. Siqueira ${ }^{a}$, M.C. Bandeca ${ }^{a}$, S.O. Costa ${ }^{a}$, M.V.S. Lemos ${ }^{c}$, V.P. Feitora ${ }^{c}$, \\ A. Reis ${ }^{\mathrm{b}}$, A.D. Loguercio ${ }^{\mathrm{b}, *}$, J.C. Gomes ${ }^{\mathrm{b}}$ \\ a Department of Postgraduate Program in Dentistry, CEUMA University, São Luis, Maranhão, Brazil \\ b Department of Restorative Dentistry, School of Dentistry, State University of Ponta Grossa, Ponta Grossa, Paraná, Brazil \\ ${ }^{\mathrm{c}}$ Department of Restorative Dentistry, School of Pharmacy, Dentistry and Nursing, Federal University of Ceará, Fortaleza, Ceará, Brazil
}

\section{A R T I C L E I N F O}

\section{Keywords:}

Adhesive systems

Dentin etching

Meta-phosphoric acid

Microtensile bond strength

Nanoleakage

Ortho-phosphoric acid

\begin{abstract}
A B S T R A C T
Purpose: To evaluate the immediate microshear resin-enamel bond strength ( $\mu \mathrm{SBS})$ and the immediate and 6 month microtensile bond strength ( $\mu \mathrm{TBS}$ ) and nanoleakage (NL) of the adhesive interface performed by different pHs of $40 \%$ meta-phosphoric acid (MPA) were compared with conventional $37 \%$ ortho-phosphoric acid (OPA) under different application times. Additionally, the enamel etching patterns were evaluated and the chemical/ morphological changes induced by these differents groups were evaluated.

Materials and methods: One hundred and ninety-eight extracted human molars were randomly assigned into experimental groups according to the combination of independent variables: Acid [37\% ortho-phosphoric acid (OPA), 40\% meta-phosphoric acid (MPA) at pHs of: 0.5, 1 and 2] and Application Time [7, 15 and 30 s]. Enamelbond specimens were prepared and tested under $\mu$ SBS. Resin-dentin beams were tested under $\mu$ TBS tested immediately or after 6-months of water storage. Nanoleakage was evaluated using bonded-beams of each tooth/ time-period. Enamel etching pattern and chemical and ultra-morphology analyses were also performed. The $\mu S B S(M P a)$ data were subjected to a two-way repeated measures ANOVA (Acid vs. Application time). For $\mu$ TBS, Acid vs application time vs storage time data were subjected to three-way ANOVA and Tukey's test $(\alpha=0.05)$. Results: MPA pH 0.5 showed $\mu$ TBS similar to OPA, independently of the application time on enamel (p $>0.05)$ or dentin ( $p>0.05)$. OPA provided higher nanoleakage values than MPA $(p=0.003)$. Significant decreases in TBS and increases in NL were only observed for OPA after 6 months ( $p=0.001)$. An increase in the application time resulted in a more pronounced etching pattern for MPA. Chemical analysis showed that dentin demineralized by MPA depicted peaks of brushite and octacalcium phosphate. MPA exposed less collagen than OPA. However, optimal results for MPA were dependent on $\mathrm{pH} / \mathrm{application}$ time.

Conclusion: The use of $40 \%$ meta-phosphoric acid with a pH of 0.5 is an alternative acid-etching agent for dentin and enamel bonding. Furthermore, the use of MPA preserves the resin-dentin interface over a 6-months period, due to presence of brushite and octacalcium phosphate and a reduced demineralization pattern.
\end{abstract}

\section{Introduction}

There is a consensus that the mechanism of bonding resin-based materials to dentin with most dental adhesives relies on micromechanical retention through forming a resin-impregnated "hybrid layer", which, upon polymerization of resin, offers a mechanical coupling zone (Nakabayashi et al., 1982; Pashley et al., 1993; Van Meerbeek et al., 1993).

Usually, an etch-and-rinse (ER) adhesive is applied by a clinician using a strong ortho-phosphoric acid etchant (32-40\%), followed by a primer and a bonding resin (3-step ER) or a combined primer and bonding resin (2-step ER) to promote adhesion. This ortho-phosphoric acid (OPA) completely demineralizes $5-8 \mu \mathrm{m}$ into the intertubular dentin matrix to create nanometer-sized porosities around collagen fibrils (Pashley et al., 2011). Furthermore, OPA also partially demineralizes to a greater depth (Feitosa et al., 2013).

Unfortunately, full infiltration of resin monomers within OPAetched dentin is a complex task. Excessive acid conditioning causes deep demineralization that jeopardizes complete infiltration of resin monomers, thereby resulting in the formation of a weaker and

\footnotetext{
* Correspondence to: Universidade Estadual de Ponta Grossa, Departamento de Odontologia, Avenida Carlos Cavalcanti, 4748 - Uvaranas, Ponta Grossa, Paraná CEP: 84030-900, Brazil.

E-mail address: aloguercio@hotmail.com (A.D. Loguercio).
} 
unprotected demineralized dentin zone at the base of these hybrid layers (Hashimoto et al., 2000, 2002b). Furthermore, the resin-dentin bonds created with contemporary hydrophilic dentin bonding systems deteriorate over time (Breschi et al., 2008; Liu et al., 2011). For ER hydrophilic adhesives, there is a decreasing gradient of resin monomer diffusion within the hybrid layers (Breschi et al., 2004; Wang and Spencer, 2002). This results in incomplete resin infiltration at the bottom the hybrid layer, leaving exposed collagen fibrils (Armstrong et al., 2004; Breschi et al., 2004; Mazzoni et al., 2006) that are susceptible to enzymatic degradation by host-derived collagen-bound matrix metalloproteinases (MMPs) (Mazzoni et al., 2006; Nishitani et al., 2006; Osorio et al., 2011) and by cysteine cathepsins (Scaffa et al., 2012).

Several approaches have been tested to inhibit the degradation of ER adhesion to dentin, but regardless the strategy used, the conditioning employed in all procedures has been OPA (Reis et al., 2013). This is because enamel etching with OPA is considered the gold standard in terms of retention and marginal seal of bonded anterior and posterior restorations (Heintze and Rousson, 2012; Mahn et al., 2015). Recently, the meta-phosphoric acid (MPA) was proposed as an alternative dentin conditioning agent for ER adhesives and a suitable strategy to create more durable resin-dentin bonds (Feitosa et al., 2013; Millan Cardenas et al., 2017).

Meta-phosphoric acid achieved successful results due its milder acidity ( $\mathrm{pH}$ around 2.6) and particular acid-ionization constant (Ka) which contributed to the creation of a thinner partially demineralized collagen layer characterized by the presence of mineral precipitation (Feitosa et al., 2013; Millan Cardenas et al., 2017). However, in a recent study, MPA was applied for $60 \mathrm{~s}$ (Feitosa et al., 2013). This long application time is in contrast to the clinician's need for simplification and rapid procedures (Reis et al., 2013). It was recently showed that lowering the $\mathrm{pH}$ of MPA reduced the application time whilst maintaining its etching pattern and immediate bonding to dentin (Millan Cardenas et al., 2017).

However, to the extent of our knowledge, the immediate resin-enamel bond, as well as the longevity of resin-dentin bond produced by MPA with different $\mathrm{pHs}$ and application times has not been evaluated. Thus, the aim of this study was to evaluate the immediate microshear resin-enamel bond strength ( $\mu \mathrm{SBS}$ ) and the immediate and 6-month microtensile resin-dentin bond strength ( $\mu \mathrm{TBS}$ ) and nanoleakage (NL) of an adhesive interface when using MPA and OPA of varying pHs and etching times. Additionally, the chemical/morphological changes induced by the use of MPA and OPA on dentin surface will be analyzed. The following null hypotheses were tested: different $\mathrm{pHs}$ and application times of the $40 \%$ meta-phosphoric acid have no difference when compared to OPA on (1) $\mu$ SBS to enamel, (2) enamel etching pattern, (3) $\mu$ TBS, (4) NL tested either immediately or after 6-months of water storage, and (5) chemical/morphological differences of etched dentin.

\section{Methods and materials}

\subsection{Tooth selection and preparation}

One hundred and ninety-eight extracted, caries-free human molars were used. The teeth were collected after obtaining the patients' informed consent. The Ethics Committee Review Board of the local university approved this research project under protocol number $1,302,629$. The teeth were disinfected in $0.5 \%$ chloramine, stored in distilled water, and used within six months after extraction.

\subsection{Experimental design}

The teeth were randomly assigned into 12 experimental conditions ( $n=60$ enamel specimens for $\mu$ SBS; 84 dentin specimens for $\mu$ TBS and NL; 21 for ATR-FTIR vibrational analysis; 21 for CLSM analysis and 12 for enamel-etching pattern evaluation) according to the combination of the independent variables: Acid [37\% of ortho-phosphoric acid (OPA; $\mathrm{pH}=0.5$, Alpha-Acid, Nova DFL, Rio de Janeiro, Brazil); $40 \%$ of metaphosphoric acid (MPA, Sigma Aldrich, St. Louis, USA) adjusted to the following pHs - 0.5, 1 and 2] and Application Time [7, 15 and 30 s]. Since specimens for $\mu$ TBS and NL were tested at different Storage Times [immediate and 6 moths], it was also considered as an independent variable.

\subsection{Microshear bond strength test ( $\mu S B S$ )}

The roots of 60 teeth were removed by sectioning at the enamelcementum junction. Each dental crown was then sectioned along the diagonals across the long axis of the tooth to produce four enamel specimens (buccal, lingual, and two proximals) (Loguercio et al., 2015). Two hundred and forty enamel specimens were embedded in a polyvinyl chloride tube $(10 \mathrm{~mm}$ high $\times 13 \mathrm{~mm}$ diameter) using a chemically cured acrylic resin (Jet Clássico, São Paulo, SP, Brazil) so that the enamel surface was left exposed at the top of the cylinder. The bonding area was isolated according to the protocol suggested by Shimaoka and others. (Shimaoka et al., 2011) Four to six perforations, with an internal diameter of $0.8 \mathrm{~mm}$, were made in an acid-resistant, double-faced adhesive tape (Adelbras Ind e Com Adesivos Ltda, São Paulo, SP, Brazil) that was adapted to the enamel surface. This procedure was performed using the Hygienic Ainsworth-style rubber-dam punch (Coltene, Alstatten, Switzerland). The variation in the number of perforations for each enamel surface was dependent on the dimensions of the enamel specimens.

The randomization of the specimens for the $\mu$ SBS testing was done using block randomization. A person not involved in the research protocol performed this procedure using computer-generated numbers. The gel etchants were applied on enamel and left in place for the appropriate application times. The surfaces were thoroughly rinsed for $60 \mathrm{~s}$ and air dried with an air spray for $5 \mathrm{~s}$ keeping the enamel moist before adhesive application. The two-steps etch-and-rinse adhesive (Ambar, FGM, Joinville, SC, Brazil) was applied strictly in accordance with the manufacturer's instructions, as described in Table 1.

After application of the adhesive system, polyethylene transparent Tygon tubes (Tygon Medical Tubing Formulations 54-HL, Saint Gobain Performance Plastics, Akron, OH, USA), with the same internal diameter as the perforations and a height of $0.5 \mathrm{~mm}$, were positioned on the perforations over the double-faced tape, ensuring that their lumen coincided with the circular areas exposed by the perforations. Resin composite (Opallis, FGM, Joinville, SC, Brazil) was carefully packed inside each tube and a clear Mylar matrix strip was placed over the filled Tygon tube and pressed gently into place. The resin composite was light cured for $20 \mathrm{~s}$ using an LED light-curing unit set at $1200 \mathrm{~mW} /$ $\mathrm{cm}^{2}$ (Radii- cal, SDI Limited, Bayswater, Victoria, Australia). A radiometer (Demetron L.E.D. Radiometer, Kerr Sybron Dental Specialties, Middleton, WI, USA) was used to check the light intensity every five specimens. These procedures were carried out under 10x magnifying loupes.

After storage of the specimens in distilled water for $24 \mathrm{~h}$ at $37^{\circ} \mathrm{C}$, the Tygon tubes and the double-faced adhesive tape were carefully removed using a blade, to expose the composite cylinders. Each specimen was examined under a stereomicroscope at $10 \times$ magnification. The bonded cylinder was discarded if there was evidence of porosities or gaps at the interface (Muñoz et al., 2014).

The specimens were attached to a shear-testing fixture (Odeme Biotechnology, Joaçaba, SC, Brazil) and tested in a universal testing machine (Kratos IKCL 3-USB, Kratos Equipamentos Industriais Ltda, Cotia, São Paulo, Brazil). Each specimen was positioned in the universal testing machine and a thin wire (0.2-mm diameter) was looped around the base of each composite cylinder. The wire contacted the composite resin cylinder along half of its circumference. The setup was maintained in alignment (resin-enamel interface, the wire loop, and the center of the load cell) to ensure the correct orientation of the shear forces 
Table 1

Dentin conditioning, $\mathrm{pH}$, conditioning time, adhesive system and composition and application Mode.

\begin{tabular}{|c|c|c|c|c|}
\hline Acid & $\mathrm{pH}$ & Conditioning time & Adhesive System (Brand)/Batch number Composition & Application mode \\
\hline $\begin{array}{l}37 \% \text { Ortho-phosphoric } \\
\text { acid (OPA) } \\
40 \% \text { Experimental meta- } \\
\text { phosphoric acid (MPA) }\end{array}$ & $\begin{array}{l}<0.5 \\
0.5 \\
1 \\
2\end{array}$ & $7 \mathrm{~s}, 15 \mathrm{~s}$ and $30 \mathrm{~s}$ & $\begin{array}{l}\text { Ambar (FGM)/271012 } \\
\text { Methacrylic monomers 10-MDP (10-methacryloyloxy } \\
\text { decyldihydrogenphosphate), photo-initiators, co-initiators, } \\
\text { stabilizer, silica nano-particulates and ethanol. }\end{array}$ & $\begin{array}{l}\text { 1. After acid conditioning, rinsing and } \\
\text { maintaining dentin slightly wet, one coat } \\
\text { of adhesive }(10 \mathrm{~s}) \text { was vigorously applied; } \\
\text { 2. Air drying }(10 \mathrm{~s}) \text { at distance; } \\
\text { 3. A second coat of the adhesive ( } 10 \mathrm{~s}) \text { was } \\
\text { vigorously applied again; } \\
\text { 4. Air drying ( } 10 \mathrm{~s}) \text { at distance; } \\
\text { 5. Light curing }(10 \mathrm{~s}) \text {. }\end{array}$ \\
\hline
\end{tabular}

(Shimada et al., 2002). The crosshead speed was set at $1 \mathrm{~mm} / \mathrm{min}$ until failure.

The $\mu$ SBS values (MPa) were calculated by dividing the load at failure by the surface area $\left(\mathrm{mm}^{2}\right)$. After testing, the specimens were examined in an optical microscope (SZH-131, Olympus Ltd, Tokyo, Japan) at $100 \times$ magnification to define the location of the bond failure. The type of failure was determined based on the percentage of substrate-free material as: cohesive [(CE) failure exclusive within enamel or (CR) failure exclusive within resin composite], adhesive/mixed [(A/ $\mathrm{M})$ failure at the resin/enamel interface, or failure at the resin/enamel interface with partial cohesive failure of the neighboring substrates], and premature failures (PF).

\subsection{Enamel-etching pattern of the OPA and MPA}

The enamel-etching pattern was evaluated using a scanning electron microscope (MIRA3, TESCAN ORSAY HOLDING, Warrendale, PA, USA). For this purpose, twelve teeth were divided into 12 groups $(\mathrm{n}=$ 4): OPA, MPA pH 0.5; MPA pH 1 and MPA pH 2. The crowns of these teeth were sectioned in the diagonals across the long axis of the tooth with a water-cooled low-speed diamond saw (Isomet 1000) in order to obtain four specimens per tooth. Each specimen was randomly allocated based on the application time (7, 15 and $30 \mathrm{~s})$. The surfaces were then rinsed off with tap water for $30 \mathrm{~s}$ and air dried with an air spray for $5 \mathrm{~s}$.

All specimens were dried and dehydrated in a desiccator for $12 \mathrm{~h}$, and the conditioned enamel surfaces were sputter coated with gold/ palladium in a vacuum evaporator (SCD 050, Balzers, Schaan, Liechtenstein). The entire surface of treated enamel was examined under a scanning electron microscope and photomicrographs of representative surface areas were taken at $1000 \times, 1200 \times$, and $5000 \times$ magnification

\subsection{Restorative procedure and dentin specimen preparation}

Prior to the restorative procedures, a flat dentin surface was exposed on each tooth after wet grinding the occlusal enamel with 180-grit SiC paper. The enamel-free, exposed dentin surfaces were further polished with 600 -grit silicon-carbide paper for $60 \mathrm{~s}$ to standardize the smear layer.

The experimental acids were applied on the surface and allowed to act on the surface based on the respective application time. After airdrying, moist dentin was left remaining, meaning that there was no movement in the pellicle of superficial water, but the dentin surface was still glistening and visibly moist. The two-step etch-and-rinse adhesive (Ambar, FGM, Joinville, Brazil) was applied according to the manufacturer's instructions, as described in Table 1. After the bonding procedures, all teeth received a micro-hybrid composite restoration (Opallis, FGM, Joinville, Brazil) in two increments of $2 \mathrm{~mm}$ each. Each increment was light-cured for $40 \mathrm{~s}$ using an LED light-curing unit set at $1200 \mathrm{~mW} / \mathrm{cm}^{2}$ (Radii-cal, SDI, Bayswater, Victoria, Australia). A single operator carried out all bonding procedures.

After storage of the bonded teeth in distilled water at $37^{\circ} \mathrm{C}$ for $24 \mathrm{~h}$, the specimens were sectioned longitudinally in both " $x$ " and " $y$ " directions across the bonded interface, using a slow-speed diamond saw (Isomet, Buehler, Lake Bluff, USA) at $300 \mathrm{rpm}$ under water cooling to obtain resin-dentin bonded sticks with a cross sectional area of approximately $0.8 \mathrm{~mm}^{2}$, which was measured using a digital caliper (Digimatic Caliper, Mitutoyo, Tokyo, Japan).

The bonded sticks originating from the same tooth were randomly assigned to be tested immediately or after 6-months of storage in distilled water at $37^{\circ} \mathrm{C}$. The distilled water was changed monthly (Skovron et al., 2010). Three resin-dentin bonded sticks from each tooth at each storage period were randomly chosen for nanoleakage testing and were further tested in the microtensile bond strength set-up.

\subsection{Microtensile bond strength test ( $\mu T B S$ )}

The cross-sectional area of each resin-dentin bonded stick was measured using a digital caliper to the nearest $0.01 \mathrm{~mm}$ and recorded for subsequent calculation of the $\mu$ TBS (Absolute Digimatic, Mitutoyo; Tokyo, Japan). At each testing time, the resin-dentin bonded sticks were attached to a Geraldeli's jig (Perdigao et al., 2002) using cyanoacrylate adhesive and tested under tension (Kratos Dinamometros, Cotia, Brazil) at $0.5 \mathrm{~mm} / \mathrm{min}$ until failure. The $\mu \mathrm{TBS}$ values (MPa) were calculated by dividing the load at failure by the cross-sectional bonding area.

The failure mode of the resin-dentin bonded sticks was evaluated under a stereomicroscope at $100 \times$ magnification (Olympus SZ40, Tokyo, Japan) and classified as either cohesive [(CD) failure exclusively within dentin or (CR) failure exclusive within resin composite] or adhesive/mixed $[(\mathrm{A} / \mathrm{M})$ failure at the resin/dentin interface, or failure at the resin/dentin interface with partial cohesive failure of the neighboring substrates]. Specimens with premature failures (PF) were included in the tooth mean for statistical analysis.

\subsection{Nanoleakage (NL) evaluation}

The selected bonded sticks were immersed in ammoniacal silver nitrate solution in darkness for $24 \mathrm{~h}$, rinsed thoroughly in distilled water, and immersed in photo-developing solution for $8 \mathrm{~h}$ under a fluorescent light to reduce silver ions into metallic silver grains within voids along the bonded interface (Tay et al., 2002). Sticks were polished with a wet 600-, 1000-, 1200-, 1500-, 2000- and 2500- grit SiC paper and 1 and $0.25 \mu \mathrm{m}$ diamond paste (Buehler, Lake Bluff, USA) using a polishing cloth. The specimens were then ultrasonically cleaned, air dried, mounted on stubs, and coated with carbon (MED 010, Balzers Union, Balzers, Liechtenstein). The resin-dentin interfaces were analyzed using a field-emission scanning electron microscope operated in the backscattered mode (VEGA3 SB, TESCAN ORSAY HOLDING, Warrendale, PA, USA).

Three images were captured from each resin-dentin bonded stick. The relative percentage of NL within the adhesive and hybrid layers in each specimen was measured in all images using the public domain Image $\mathrm{J}$ software, a Java-based image processing software package developed at the National Institutes of Health (NIH) (Schneider et al., 
2012) by a blinded researcher (Reis et al., 2007). The mean NL of all sticks from the same tooth was averaged for statistical purposes.

\subsection{ATR-FTIR vibrational analysis}

Twenty-one teeth were used for the qualitative chemical composition analysis of etched dentin. Each tooth was transversally sectioned two millimeters above the cementum-enamel junction and longitudinally in the mesial-distal direction across the occlusal surface, using a slow-speed diamond saw (Isomet, Buehler, Lake Bluff, USA) to obtain three flat dentin specimens.

Specimens were randomized based on each application time $(7,15$ or $30 \mathrm{~s})$ and acid (MPA or OPA) ( $\mathrm{n}=3$ ). After etching as previously reported in the $\mu$ TBS section, all specimens were thoroughly rinsed for $60 \mathrm{~s}$ and gently air-dried. Further, non-etched and sound dentin specimens $(\mathrm{n}=3)$ were prepared and analyzed.

FTIR analysis was performed with wet dentin, as previously described, using the ATR-FTIR Spectrometer (Perkin-Elmer Spectrum One; Perkin-Elmer, Beaconsfield, UK) in the region of $650-4000 \mathrm{~cm}^{-1}$, a resolution of $4 \mathrm{~cm}^{-1}$, and 32 scans for each specimen. The ATR area was $2-\mathrm{mm}$ diameter and the IR radiation penetration was approximately 3-5 $\mu \mathrm{m}$. In order to place the specimens in good contact with the ATR crystal, moderate pressure was applied (5 psi) during the measurement to achieve high quality results, but at the same time, to avoid compression of the demineralized collagen to the underlying mineralized dentin. A control ATR-FTIR analysis was performed for the commercial high purity ( $>97 \%$ ) brushite (Sigma-Aldrich). To minimize the homogeneity variability of the specimens, three spectra were recorded in different positions of the surface, which were normalized and the baseline correction was performed (Feitosa et al., 2013; Sauro et al., 2013).

\subsection{Collagen-staining confocal microscopy analysis (CLSM)}

Twenty-one teeth were used to evaluate the morphology features induced by different experimental conditions. This experiment was prepared as previously described for ATR-FTIR-analysis and submitted to the dye-assisted collagen-staining confocal microscopy analysis (CLSM) (Feitosa et al., 2013; Profeta et al., 2013). The specimens were immediately immersed in a $0.5 \mathrm{wt} \%$ collagen-binding $0.1 \mathrm{wt} \%$ dye water/ethanol $(50 \mathrm{v} \% / 50 \mathrm{v} \%)$ solution (FITC - fluorescein isothiocyanate; Sigma-Aldrich) for $24 \mathrm{~h}$ at $37^{\circ} \mathrm{C}(\mathrm{pH}$ 7.2) (Fujisawa and Kuboki, 1992). Subsequent to the dye immersion, the specimens were copiously rinsed with water and treated in an ultrasonic water-bath for $5 \mathrm{~min}$ and then submitted to confocal microscopy evaluation. The confocal microscopy analysis was performed using a confocal-laser scanning microscope (LM 710 Confocal; Carl Zeiss, Oberkochen, Germany) equipped with a $63 \mathrm{x} / 1.4 \mathrm{NA}$ oil immersion lens and a $488-\mathrm{nm}$ Argon/Krypton ions laser (fluorescein excitation). The emission fluorescence was recorded at $512-538 \mathrm{~nm}$; control dentin (sound - no treatment) specimens were also surveyed in the CLSM analysis. CLSM images were obtained with a $0.5 \mu \mathrm{m}$ Z-step (Z-stack) or X-step (X-stack) to optically section the specimens to a depth up to $25 \mu \mathrm{m}$. The Z-stack and X-stack scans performed along the interface were arbitrarily pseudo-coloured by an operator and compiled into single projections or 3D images using the Zeiss image-processing software (Feitosa et al., 2013). Throughout the entire research, the standardized configuration of the system was used. Each slab was totally analyzed and micrographs representing the most common features observed along the surface and an estimation of the thickness of demineralized dentin collagen were captured and recorded.

\subsection{Statistical analysis}

The $\mu$ SBS (MPa) means for every testing group was expressed as the average of five teeth per group. The resin-enamel $\mu$ SBS values obtained from the same enamel specimen were averaged for statistical purposes. The $\mu$ SBS (MPa) data were subjected to a two[HYPHEN] way repeated measures ANOVA (Acid vs. Application time). The $\mu S B S$ (MPa) data were subjected to a two[HYPHEN]way repeated measures ANOVA (Acid vs. Application time). The $\mu$ TBS and NL of all bonded sticks from the same hemi-tooth were averaged for statistical purposes. The $\mu$ TBS (MPa) and NL (\%) means for every testing group was expressed as the average of seven hemi-teeth used per group. The $\mu \mathrm{TBS}$ (MPa) and NL (\%) data were subjected to a three-way repeated measures ANOVA (Acid vs. Application time vs. Storage time). All data were submitted to a post hoc test (Tukey's post hoc test at $\alpha=0.05$ ) for pair-wise comparisons. The enamel-etching pattern, chemical interaction and ultramorphological characterization were only qualitatively evaluated.

\section{Results}

\subsection{Micro-shear bond strength test ( $\mu S B S$ )}

The percentage of specimens with premature failures and the frequency of each fracture pattern mode are shown in Table 2. Few premature $(2.1 \%)$ and no cohesive failures $(0.0 \%)$ were observed. Most of the specimens showed adhesive or adhesive/mixed failures.

The cross-product interaction of acid vs. application time was statistically significant $(\mathrm{p}=0.001)$. The MPA with $\mathrm{pH} 0.5$ produced statistically higher $\mu$ TBS values when compared to MPA with pH 2 at $15 \mathrm{~s}$ and $30 \mathrm{~s}$ application times ( $<<0.001$; Table 3). MPA with $\mathrm{pH} 1$ and 2

Table 2

Number of specimens (percentage) according to fracture mode for all experimental groups in enamel (").

\begin{tabular}{|c|c|c|c|c|c|c|}
\hline \multirow[t]{2}{*}{ Enamel conditioning } & \multirow[t]{2}{*}{$\mathrm{pH}$} & \multirow[t]{2}{*}{ Application time } & \multicolumn{4}{|c|}{ Fracture mode } \\
\hline & & & $\mathbf{A} / \mathbf{M}$ & $\mathrm{CE}$ & CR & $\mathbf{P F}$ \\
\hline \multirow[t]{3}{*}{$37 \%$ Ortho-phosphoric acid (OPA) } & $<1$ & $7 \mathrm{~s}$ & $84(98)$ & $0(0)$ & $0(0)$ & $2(2)$ \\
\hline & & $15 s$ & $82(100)$ & $0(0)$ & $0(0)$ & $0(0)$ \\
\hline & & $30 \mathrm{~s}$ & $86(100)$ & $0(0)$ & $0(0)$ & $0(0)$ \\
\hline \multirow[t]{9}{*}{ 40\% Meta-phosphoric acid (MPA) } & 0.5 & $7 \mathrm{~s}$ & $91(98)$ & $0(0)$ & $0(0)$ & $2(2)$ \\
\hline & & $15 s$ & $85(100)$ & $0(0)$ & $0(0)$ & $0(0)$ \\
\hline & & $30 s$ & $95(100)$ & $0(0)$ & $0(0)$ & $0(0)$ \\
\hline & 1 & $7 \mathrm{~s}$ & $86(98)$ & $0(0)$ & $0(0)$ & $2(2)$ \\
\hline & & $15 s$ & $100(100)$ & $0(0)$ & $0(0)$ & $0(0)$ \\
\hline & & $30 \mathrm{~s}$ & 95 (95) & $0(0)$ & $0(0)$ & $5(5)$ \\
\hline & 2 & $7 \mathrm{~s}$ & $80(96)$ & $0(0)$ & $0(0)$ & $3(4)$ \\
\hline & & $15 s$ & 85 (94) & $0(0)$ & $0(0)$ & $5(6)$ \\
\hline & & $30 \mathrm{~s}$ & $92(96)$ & $0(0)$ & $0(0)$ & $4(4)$ \\
\hline
\end{tabular}

* A/M - adhesive/mixed fracture mode; CE - cohesive-enamel fracture mode; CR - cohesive-resin fracture mode; $\mathrm{PF}$ - premature failure 
Table 3

Microshear bond strength (MPa) values (means \pm standard deviations) of the different experimental groups (").

\begin{tabular}{|c|c|c|c|c|}
\hline \multirow[t]{2}{*}{ Acid } & \multirow[t]{2}{*}{$\mathrm{pH}$} & \multicolumn{3}{|l|}{ Application time } \\
\hline & & $7 \mathrm{~s}$ & $15 s$ & $30 \mathrm{~s}$ \\
\hline 37\% Ortho-phosphoric acid & $<0.5$ & $20.1 \pm 1.1$ a A,B & $23.2 \pm 1.3 \mathrm{a} \mathrm{A}$ & $17.0 \pm 1.2 \mathrm{~b} \mathrm{~A}$ \\
\hline \multirow{3}{*}{ 40\% Meta-phosphoric acid (MPA) } & 0.5 & $16.8 \pm 1.6$ a,b B & $22.4 \pm 1.0 \mathrm{a} \mathrm{A}$ & $21.3 \pm 1.7$ a A \\
\hline & 1 & $12.2 \pm 0.9 \mathrm{~b} \mathrm{~A}$ & $14.2 \pm 0.7$ a $B$ & $13.1 \pm 1.2 \mathrm{a} \mathrm{B}$ \\
\hline & 2 & $10.6 \pm 2.0 \mathrm{~b} \mathrm{~B}$ & $9.2 \pm 1.0 \mathrm{~b} \mathrm{C}$ & $13.0 \pm 1.3$ a $\mathrm{B}$ \\
\hline
\end{tabular}

* Different small case letters within each column and capital case letters across each row means statistically different (Two-way ANOVA and Tukey test; $\mathrm{p}<0.05$ ).

did not present significant differences between them ( $p>0.05$; Table 3). The increase in application time resulted in statistically significant higher $\mu$ TBS values only for MPA with pH 0.5 (15 and $30 \mathrm{~s}$ ) and 2 (30 s) (p < 0.001; Table 3). Only MPA pH 0.5 showed $\mu$ SBS means similar to OPA, independently of the application time $(\mathrm{p}>0.05$; Table 3).

\subsection{Enamel-etching pattern of the OPA and MPA}

SEM images of the enamel surfaces after conditioning with OPA and MPA are presented in Fig. 1. OPA resulted in the deepest and most pronounced etching pattern when compared with MPA, independent of the time of application (Fig. 1). When OPA was applied for $7 \mathrm{~s}$, the preferential dissolution of the prism wall was observed. When OPA was applied for more time, the enamel surface showed more morphological alteration of the prisms, forming a porous surface (Fig. 1).
Application of MPA resulted in exposure of the periphery of the prisms, with signs of hydroxyapatite dissolution. When MPA with $\mathrm{pH}$ 0.5 was applied for $30 \mathrm{~s}$, partial dissolution of the prisms with an exposure of the subsurface enamel was observed. MPA with $\mathrm{pH} 1$ and 2 resulted in a featureless morphology in which the superficial enamel layer was removed without exposure of the subsurface enamel. When the application time was increased, there was a more pronounced etching pattern. (Fig. 1)

\subsection{Microtensile bond strength test ( $\mu$ TBS)}

The percentage of specimens with premature failure and the frequency of each fracture pattern mode are shown in Table 4. Few premature $(4.1 \%)$ and cohesive failures $(0.4 \%)$ were observed. Most of the specimens showed adhesive or adhesive/mixed failures.

The cross-product interaction of acid vs. application time vs. storage
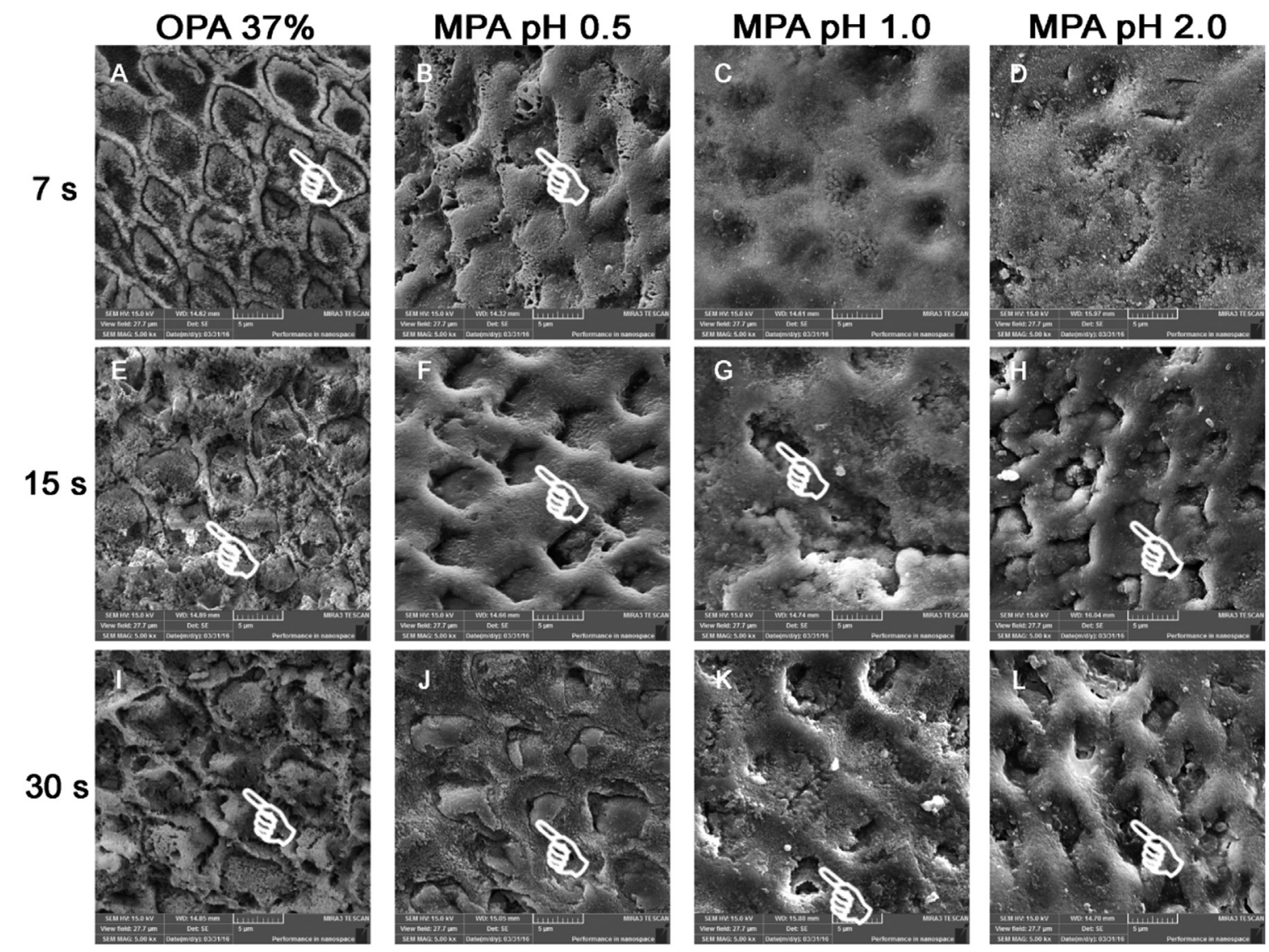

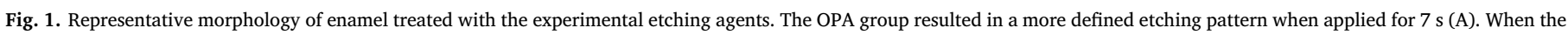

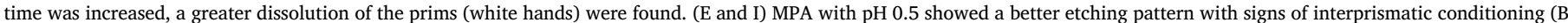

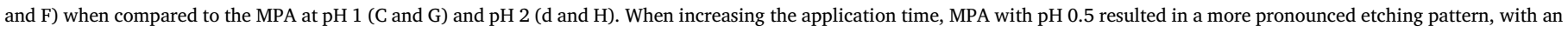
exposure of the subsurface enamel (white hands) (J). 
Table 4

Number of specimens (percentage) according to fracture mode for all experimental groups in dentin (").

\begin{tabular}{|c|c|c|c|c|c|c|c|c|c|c|}
\hline \multirow[t]{2}{*}{ Dentin conditioning } & \multirow[t]{2}{*}{$\mathrm{pH}$} & \multirow[t]{2}{*}{ Application time } & \multicolumn{4}{|c|}{ Immediate } & \multicolumn{4}{|l|}{ 6.month } \\
\hline & & & $\mathrm{A} / \mathrm{M}$ & $\mathrm{CD}$ & $\mathrm{CR}$ & $\mathrm{PF}$ & $\mathrm{A} / \mathrm{M}$ & $\mathrm{CD}$ & CR & $\mathrm{PF}$ \\
\hline \multirow[t]{3}{*}{$37 \%$ Ortho-phosphoric acid (OPA) } & \multirow[t]{3}{*}{$<0.5$} & $7 \mathrm{~s}$ & $55(97)$ & $0(0)$ & $0(0)$ & $2(3)$ & $49(86)$ & $0(0)$ & $0(0)$ & $8(14)$ \\
\hline & & $15 \mathrm{~s}$ & $59(94)$ & $0(0)$ & $2(3)$ & $2(3)$ & $52(93)$ & $0(0)$ & $0(0)$ & $4(7)$ \\
\hline & & $30 \mathrm{~s}$ & $57(95)$ & $0(0)$ & $0(0)$ & $3(5)$ & $58(92)$ & $0(0)$ & $0(0)$ & $5(8)$ \\
\hline \multirow[t]{9}{*}{$40 \%$ Meta-phosphoric acid (MPA) } & \multirow[t]{3}{*}{0.5} & $7 \mathrm{~s}$ & $55(95)$ & $0(0)$ & $0(0)$ & $3(5)$ & $54(98)$ & $0(0)$ & $0(0)$ & $1(2)$ \\
\hline & & $15 \mathrm{~s}$ & $60(98)$ & $0(0)$ & $0(0)$ & $1(2)$ & $62(100)$ & $0(0)$ & $0(0)$ & $0(0)$ \\
\hline & & $30 \mathrm{~s}$ & $57(95)$ & $0(0)$ & $0(0)$ & $3(5)$ & $59(97)$ & $0(0)$ & $0(0)$ & $2(3)$ \\
\hline & \multirow[t]{3}{*}{1.0} & $7 \mathrm{~s}$ & $48(89)$ & $0(0)$ & $1(2)$ & $5(9)$ & $62(98)$ & $0(0)$ & $0(0)$ & $1(2)$ \\
\hline & & $15 \mathrm{~s}$ & 64(97) & $0(0)$ & $0(0)$ & $2(3)$ & $59(95)$ & $0(0)$ & $0(0)$ & $3(5)$ \\
\hline & & $30 \mathrm{~s}$ & $57(97)$ & $0(0)$ & $2(3)$ & $0(0)$ & $61(100)$ & $0(0)$ & $0(0)$ & $0(0)$ \\
\hline & \multirow[t]{3}{*}{2.0} & $7 s$ & $40(87)$ & $0(0)$ & $0(0)$ & $6(13)$ & $52(100)$ & $0(0)$ & $0(0)$ & $0(0)$ \\
\hline & & $15 \mathrm{~s}$ & $62(95)$ & $0(0)$ & $0(0)$ & $1(5)$ & $55(96)$ & $0(0)$ & $0(0)$ & $2(4)$ \\
\hline & & $30 \mathrm{~s}$ & 59(97) & $0(0)$ & $0(0)$ & $2(3)$ & $56(98)$ & $0(0)$ & $1(2)$ & $0(0)$ \\
\hline
\end{tabular}

* $\mathrm{A} / \mathrm{M}=$ adhesive-mixed $\mathrm{CD}=$ cohesive fracture mode in dentin; $\mathrm{CR}=$ cohesive fracture mode in resin and; $\mathrm{PT}=$ premature failures

Table 5

Microtensile resin-dentin bond strength (MPa) values (means \pm standard deviations) of the different experimental groups ( $)$.

\begin{tabular}{|c|c|c|c|c|c|c|c|}
\hline \multirow[t]{3}{*}{ Acid } & \multirow[t]{3}{*}{ pH } & \multicolumn{6}{|c|}{ Application time } \\
\hline & & \multicolumn{2}{|l|}{$7 \mathrm{~s}$} & \multicolumn{2}{|l|}{$15 s$} & \multicolumn{2}{|l|}{$30 \mathrm{~s}$} \\
\hline & & Immediate & 6 month & Immediate & 6 month & Immediate & 6 month \\
\hline 37\% Ortho-phosphoric acid (OPA) & $<0.5$ & $35.9 \pm 1.5$ a B & $26.3 \pm 2.5 \mathrm{~b} \mathrm{C}$ & $42.4 \pm 1.2$ a B & $29.9 \pm 2.5$ b C & $51.0 \pm 2.1$ a $A$ & $29.6 \pm 2.4 \mathrm{~b} \mathrm{C}$ \\
\hline \multirow[t]{3}{*}{$40 \%$ Meta-phosphoric acid (MPA) } & 0.5 & $32.1 \pm 1.4$ a B & $32.7 \pm 5.4$ a B & $45.4 \pm 2.4$ a A & $42.1 \pm 1.5$ a A & $46.3 \pm 1.0$ a $\mathrm{A}$ & $40.3 \pm 3.1$ a $A$ \\
\hline & 1 & $32.2 \pm 3.5$ a B & $31.3 \pm 2.3$ a B & $30.8 \pm 1.6 \mathrm{~b} \mathrm{~B}$ & $28.5 \pm 2.2 \mathrm{~b} \mathrm{~B}$ & $40.8 \pm 2.7 \mathrm{~b} \mathrm{~A}$ & $39.3 \pm 2.7$ a $\mathrm{A}$ \\
\hline & 2 & $17.3 \pm 1.1 \mathrm{~b} \mathrm{~B}$ & $21.8 \pm 2.9$ с B & $32.6 \pm 1.1 \mathrm{~b} \mathrm{~A}$ & $30.6 \pm 2.3 \mathrm{~b} \mathrm{~A}$ & $30.2 \pm 1.8 \mathrm{c} \mathrm{A}$ & $32.5 \pm 4.6 \mathrm{~b} \mathrm{~A}$ \\
\hline
\end{tabular}

* Different small case letters within each column and capital case letters across each row means statistically different (Three-way ANOVA and Tukey test; $\mathrm{p}<0.05$ ).
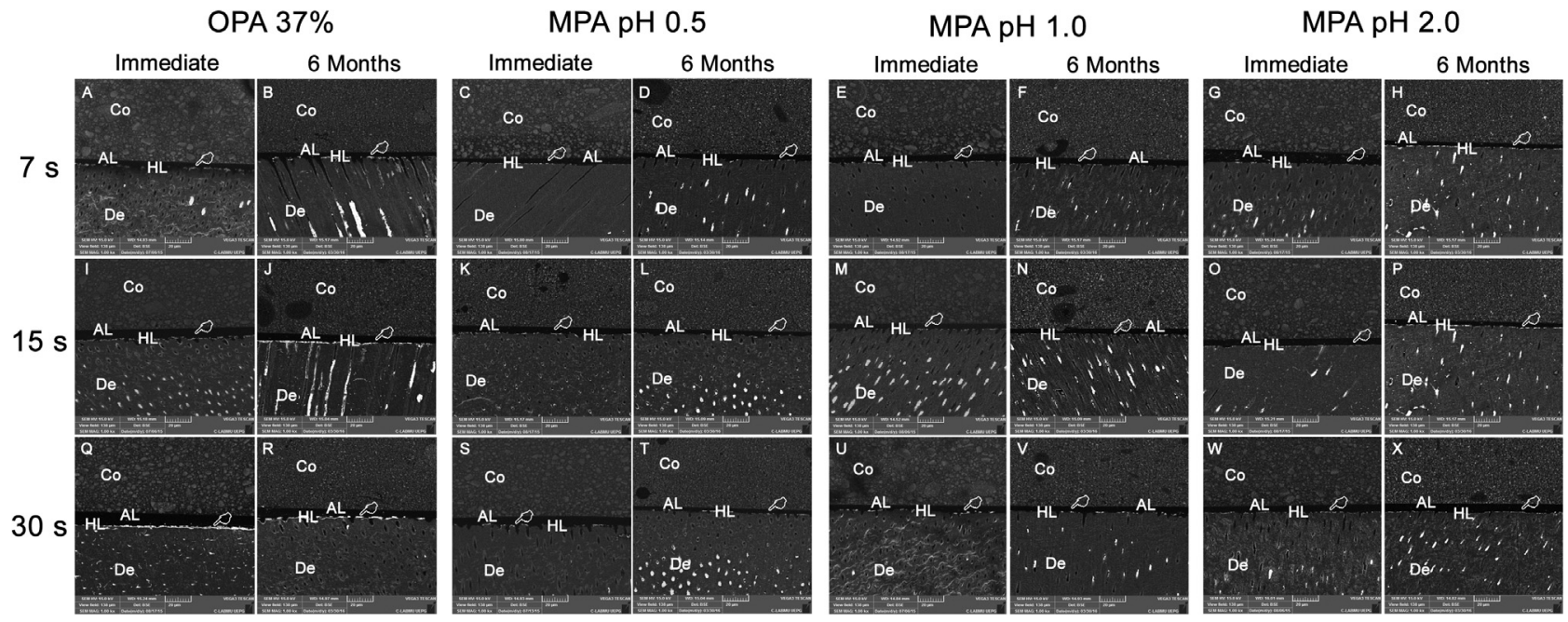

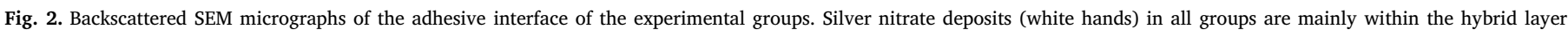

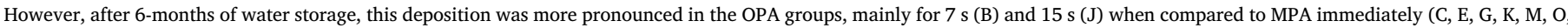
$\mathrm{S}, \mathrm{U}, \mathrm{W}$ ) and after 6-months water storage (D, F, H, L, N, P, T, V, X) Co = composite resin; AL = adhesive layer; HL = hybrid layer; De = dentin).

time was statistically significant $(\mathrm{p}=0.001)$. MPA with $\mathrm{pH} 0.5$ produced statistically higher $\mu$ TBS values when compared to MPA with $\mathrm{pH}$ 2 at each application time ( $\mathrm{p}=0.001$; Table 5$)$. MPA with $\mathrm{pH} 1$ showed intermediary results ( $\mathrm{p}>0.05$; Table 5$)$. The increase in application time resulted in statistically significantly higher $\mu$ TBS values only for MPA with pH 0.5 and 2 (15 and $30 \mathrm{~s}$ ) and 1 (30 s) (p < 0.001; Table 5). MPA with $\mathrm{pH} 0.5$ showed $\mu$ TBS means similar to OPA, independently of the application time ( $\mathrm{p}>0.05$; Table 5).

However, significant decreases of $\mu$ TBS were only observed for OPA after 6 months of water storage ( $p=0.001$; Table 5). Regarding MPA and independently of $\mathrm{pH}$ or application times, the $\mu \mathrm{TBS}$ was stable after 6-months of water storage ( $p>0.05$; Table 5).

\subsection{Nanoleakage (NL) evaluation}

Fig. 2 shows the minimal nanoleakage at 6-months when MPA was applied. The cross-product interaction of acid vs. application time vs. storage time, as well as application time vs. storage time was not statistically significant ( $p=0.99$ and 0.47 , respectively). On the other hand, the cross-product interactions of acid vs. application time and acid vs. storage time were statistically significant $(\mathrm{p}=0.003$ and 0.01 , respectively). 
Table 6

Nanoleakage (\%) values (means \pm standard deviations) of the different experimental groups (").

\begin{tabular}{|c|c|c|c|c|c|c|c|}
\hline \multirow[t]{3}{*}{ Acid } & \multirow[t]{3}{*}{$\mathrm{pH}$} & \multicolumn{6}{|c|}{ Application time } \\
\hline & & \multicolumn{2}{|l|}{$7 s$} & \multicolumn{2}{|l|}{$15 s$} & \multicolumn{2}{|l|}{$30 \mathrm{~s}$} \\
\hline & & Immediate & 6 month & Immediate & 6 month & Immediate & 6 month \\
\hline 37\% Ortho-phosphoric acid & $<0.5$ & $13.1 \pm 3.1 \mathrm{~b} \mathrm{~A}$ & $17.5 \pm 2.8 \mathrm{~b} \mathrm{~B}$ & $16.1 \pm 2.5 \mathrm{~b} \mathrm{~B}$ & $19.2 \pm 2.7 \mathrm{~b} \mathrm{C}$ & $18.2 \pm 1.9 \mathrm{~b} \mathrm{~B}$ & $21.2 \pm 1.7 \mathrm{~b} \mathrm{~B}$ \\
\hline \multirow[t]{3}{*}{$40 \%$ Meta-phosphoric acid (MPA) } & 0.5 & $6.7 \pm 1.5$ a A & $7.3 \pm 1.9$ a A & $6.9 \pm 2.0$ a $\mathrm{A}$ & $7.8 \pm 1.9$ a A & $7.8 \pm 1.3$ a A & $7.4 \pm 2.0 \mathrm{a} \mathrm{A}$ \\
\hline & 1 & $6.9 \pm 1.8$ a $\mathrm{A}$ & $7.9 \pm 2.1$ a A & $7.1 \pm 1.9$ a $\mathrm{A}$ & $8.3 \pm 2.5$ a $\mathrm{A}$ & $8.2 \pm 1.3$ a $\mathrm{A}$ & $8.1 \pm 1.0$ a $\mathrm{A}$ \\
\hline & 2 & $7.3 \pm 3.0$ a A & $8.3 \pm 1.9$ a A & $7.1 \pm 1.8$ a A & $8.2 \pm 1.3 \mathrm{a} \mathrm{A}$ & $7.7 \pm 2.0 \mathrm{a} \mathrm{A}$ & $7.9 \pm 1.5$ a A \\
\hline
\end{tabular}

* Different small case letters within each column and capital case letters across each row means statistically different (Three-way ANOVA and Tukey test; $\mathrm{p}<0.05$ ).

For OPA at all application times, higher NL was found when compared with MPA ( $\mathrm{p}=0.003$; Table 6$)$ which also increased after 6months of storage time, mainly for the 7 and $15 \mathrm{~s}$ application times (p $=0.01$; Table 6). For all MPA acids evaluated, the application time did not show any significant changes in the NL ( $p>0.05$; Table 6). Also after 6-months of water storage, all NL values remained unchanged (p > 0.05; Table 6). Fig. 2 shows the minimal nanoleakage at immediate and after 6-months when MPA was applied.

\subsection{ATR-FTIR vibrational analysis (ATR-FTIR)}

Fig. 3 depicts the spectra from commercial brushite powders, as well as the dentin surface before and after treatment with OPA and MPA for different application times and pHs. The PO stretching peaks of the commercial brushite can be seen at 1134, 1057, and $987 \mathrm{~cm}^{-1}$. These specific peaks were not observed in dentin demineralized by OPA. On the other hand, in the dentin treated with MPA at $\mathrm{pH}$ 1.0, brushite peaks were shown (Fig. 3C). Some signs of brushite were also present with MPA at $\mathrm{pH} 0.5$. Unexpectedly, MPA at $\mathrm{pH} 2$, especially when applied for $30 \mathrm{~s}$, depicted a strong peak at $1030 \mathrm{~cm}^{-1}$ with a shoulder in $1130 \mathrm{~cm}^{-1}$ (Fig. 3D), as described by Murakami et al. (2010) as characteristic of octacalcium phosphate (OCP).

However, these peaks varied in intensity. Usually, the dentin surface treated with lower pH MPA showed only low intensity peaks of phosphate at 1134,1057 , and $987 \mathrm{~cm}^{-1}$, when compared to higher $\mathrm{pH}$ MPA-treated dentin, with lower demineralization. In summary, The FTIR spectra results showed the presence of brushite and OCP after etching the dentin with MPA, but it was dependent of $\mathrm{pH}$ and application time.
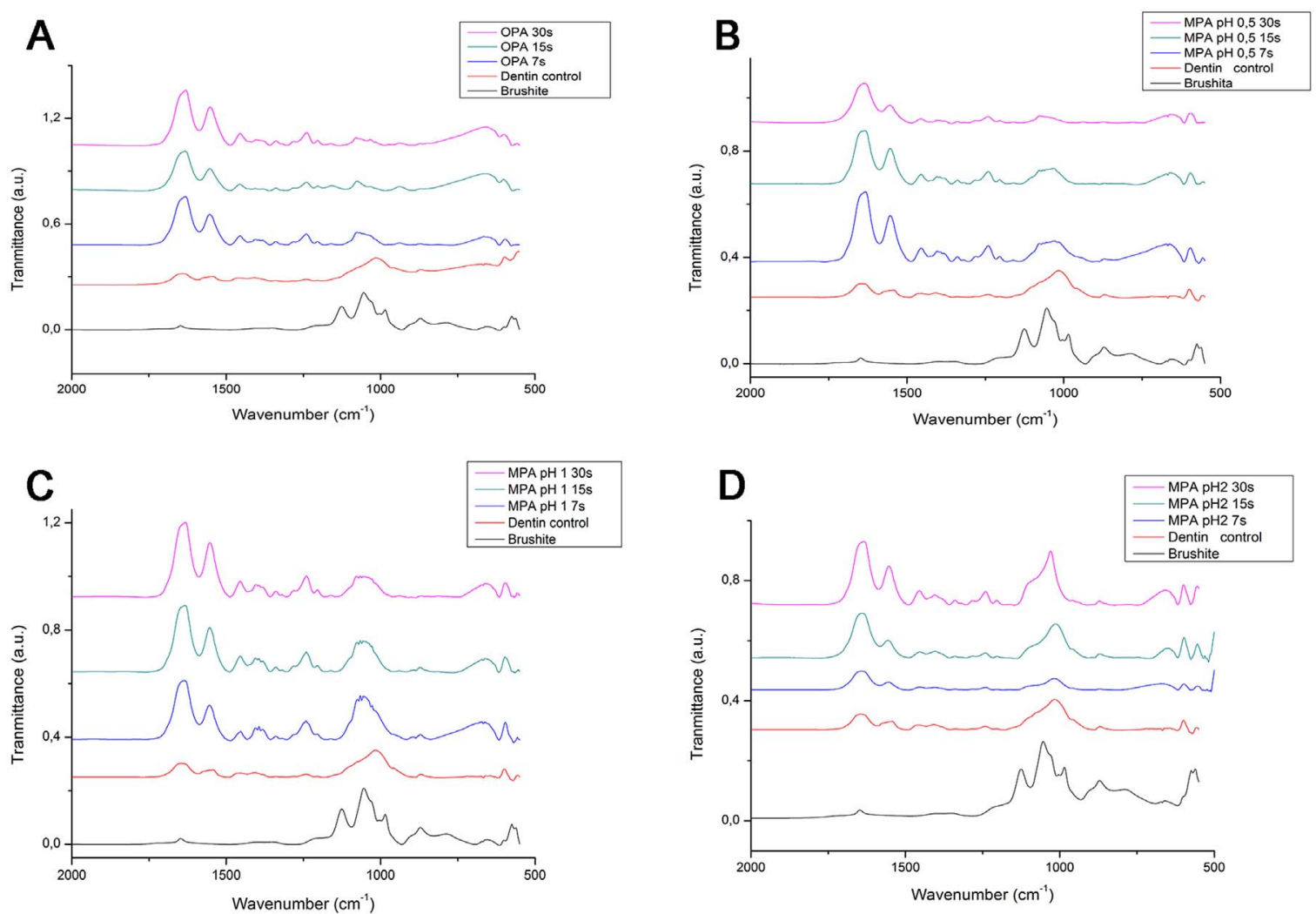

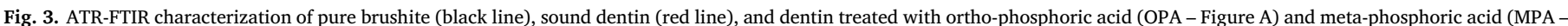

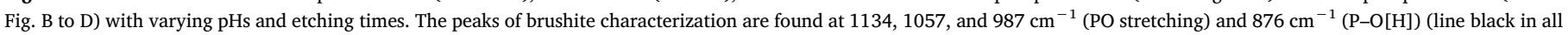

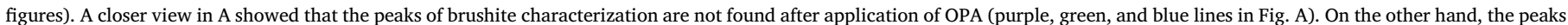

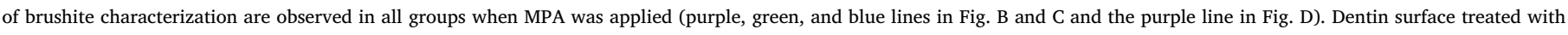

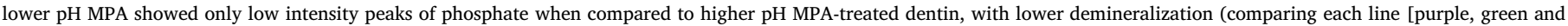

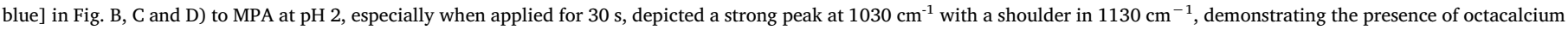
phosphate. (For interpretation of the references to color in this figure legend, the reader is referred to the web version of this article). 


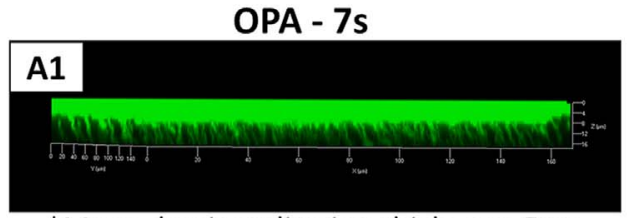

*Mean demineralization thickness: $5 \mu \mathrm{m}$

OPA - 15s

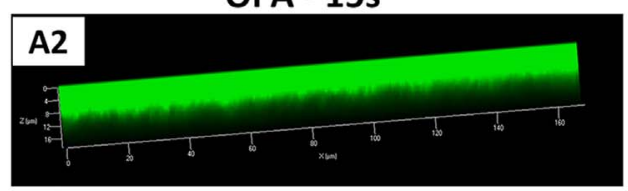

*Mean demineralization thickness: $9 \mu \mathrm{m}$

OPA - 30s

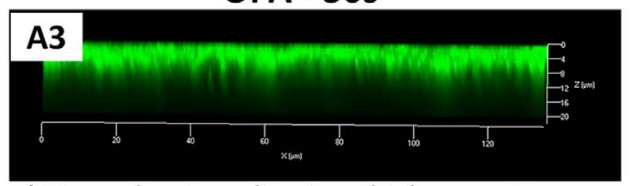

*Mean demineralization thickness: $11 \mu \mathrm{m}$

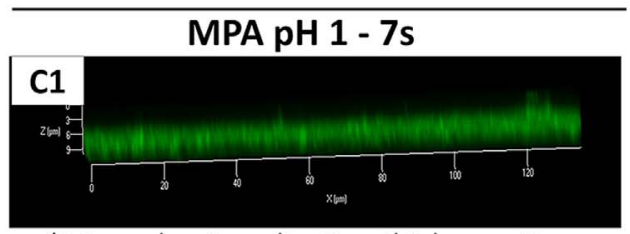

*Mean demineralization thickness: $3 \mu \mathrm{m}$

MPA pH 1 - 15s

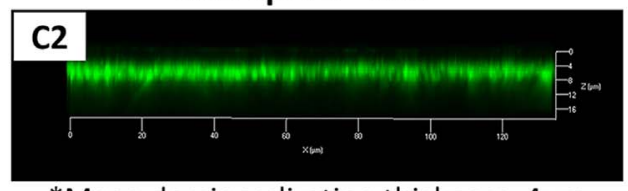

*Mean demineralization thickness: $4 \mu \mathrm{m}$

MPA pH 1 - 30s

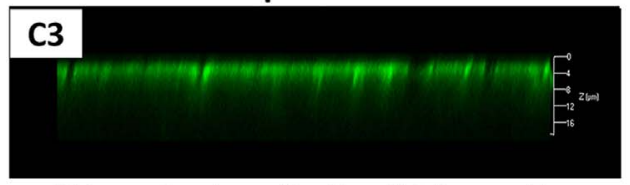

*Mean demineralization thickness: $7 \mu \mathrm{m}$
MPA pH $0.5-7 s$

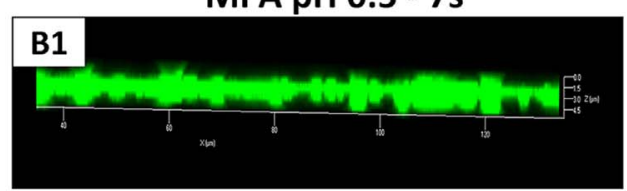

*Mean demineralization thickness: $3 \mu \mathrm{m}$

MPA pH 0.5 - 15s

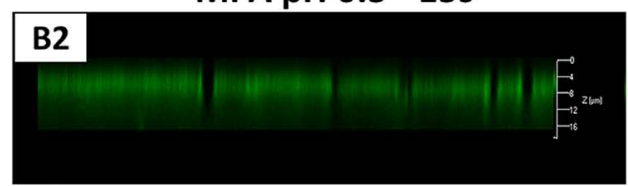

*Mean demineralization thickness: $6 \mu \mathrm{m}$
Fig. 4. Collagen-staining confocal microscopy analysis of the dentin specimens treated with orthophosphoric acid (OPA) and, meta-phosphoric acid (MPA) with varying $\mathrm{pHs}$ and etching times. Independent of the time application, OPA showed a more pronounced mean of demineralization thickness (Fig. A1-A3). For MPA at pH 0.5, $2 \mu \mathrm{m}$ less collagen demineralization thickness was observed when compared to OPA in the same etching times. (Fig. A1-A3). For MPA at $\mathrm{pH} 1$ (Fig. C1-C3) and $\mathrm{pH}$ 2 (Fig. D1-D3), minor differences were found for the same etching times.

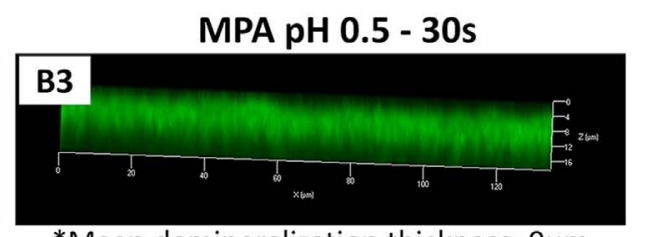

*Mean demineralization thickness: $9 \mu \mathrm{m}$

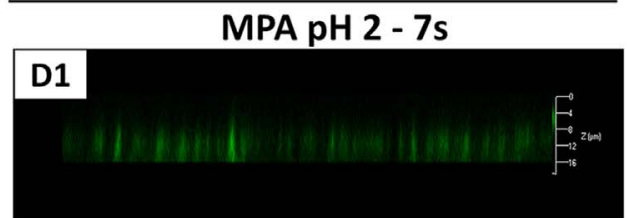

*Mean demineralization thickness: $2 \mu \mathrm{m}$

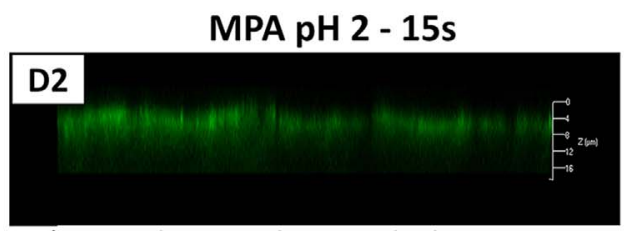

*Mean demineralization thickness: $4 \mu \mathrm{m}$

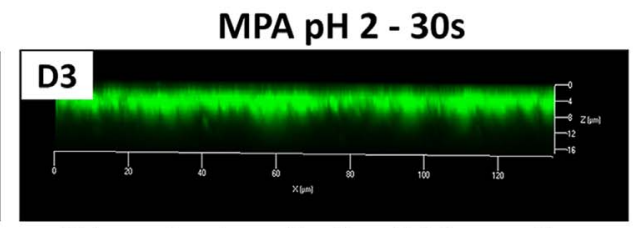

*Mean demineralization thickness: $6 \mu \mathrm{m}$

\subsection{Collagen-staining confocal microscopy analysis (CLSM)}

Fig. 4 shows the CLSM-Collagen analysis of the dentin specimens treated with OPA and MPA and stained with FITC. The mean demineralization thicknesses are presented in Fig. 4. Overall, OPA treatment promoted deeper demineralization. Minor differences were found between MPA at $\mathrm{pH} 1$ and $\mathrm{pH} 2$ at the same etching times. At pH 0.5, MPA induced an average of $2 \mu \mathrm{m}$ less collagen demineralization thickness than OPA at the same etching times.

\section{Discussion}

In the present study, an increase in application time did not significantly change resin-enamel $\mu$ SBS values for OPA. However, higher resin-enamel $\mu$ SBS values for MPA were observed when longer application times were performed, which leads us to reject the first null hypothesis. Additionally, the increase of application time significantly changed the enamel etching pattern for OPA and MPA, which leads us to reject the second null hypothesis

A contact time between 15 and $30 \mathrm{~s}$ for OPA application has been confirmed by use for many years, because a longer conditioning time with OPA creates a deeper etching pattern (Guba et al., 1994; Oliver, 1987; Tsujimoto et al., 2016a, 2016b). Several recent studies showed that the provided etching pattern featured no influence on the resinenamel bond strength, since a shortened conditioning time with OPA creates an adequate micromechanical retentive enamel surface and, consequently, higher resin-enamel bond strength values (Barkmeier et al., 2009; Kimmes et al., 2010; Tsujimoto et al., 2016a, 2016b, 2017), as observed in the results of the present study.

On the other hand, higher resin-enamel bond strength values were obtained for MPA when a longer application time was used. The characteristics of MPA differ in many aspects from OPA. MPA has only one hydrogen ion available for deprotonation when compared with the three protonable hydrogen ions present in OPA, which gives MPA the 
particular acid ionization constant $(\mathrm{Ka})\left(3.98 \times 10^{-13}\right)$ in relation to OPA - $\left(7.25 \times 10^{-3}\right)$. Thus, Ka-OPA is considered stronger than KaMPA, which contributed to the lower demineralization pattern of enamel (Fig. 1). This softer Ka-MPA can also be responsible for the thinner enamel etching pattern when compared to OPA, especially when MPA at $\mathrm{pH} 1$ and 2 were applied (Fig. 1), in a manner similar to that occurring with dentin (Feitosa et al., 2013).

It worth to mentioning that decreasing the $\mathrm{pH}$ of MPA significantly increased the dentin conditioning pattern for MPA, as observed in the results of CLSM. The current authors speculate that etching pattern significantly increased the resin-enamel SBS values. Additionally, the acidic MPA ( $\mathrm{pH} 0.5)$ reached similar bond strength values to the enamel and dentin substrates when compared to OPA.

On the other hand, the increase in application time resulted in higher resin-dentin $\mu$ TBS values for MPA and OPA, leading us to partially reject the third null hypothesis. These results agree with previous studies on permanent and primary teeth for OPA (Lenzi et al., 2014; Osorio et al., 2010; Scheffel et al., 2013) and MPA (Millan Cardenas et al., 2017). However, there was a significant difference in the nanoleakage results, since increasing the application time resulted in a significantly higher mean of nanoleakage for OPA. However, no significant changes in nanoleakage were observed for MPA, leading us to partially reject the third null hypothesis.

A longer application time promoted more dissolution of the smear layer on the dentin surface for resin monomer diffusion, allowing mechanical interlocking (Botelho et al., 2017; Reis et al., 2013, 2008), and consequently higher resin-dentin $\mu$ TBS for MPA and OPA. On the other hand, these voids could be not completely infiltrated by resin monomers (Hashimoto et al., 2000, 2002b). When the dentin is etched with OPA, the extra-fibrillar and intra-fibrillar mineral of dentin surfaces are totally dissolved, even in $\mathrm{pH} 0.5$ as used in the present study, which may increase the risk for demineralized fibrils to dehydrate and collapse during the bonding procedures establishing chemical interactions through hydrogen bonding (El Feninat et al., 2001). When a longer application time was applied for OPA, deeper decalcification of both intertubular and peritubular dentin was presented (Hashimoto et al., 2002b; Perdigao and Lopes, 2001), as observed in the current CLSM analysis. Therefore, the complete resin monomer diffusion, particularly those with high molecular weight, is limited into demineralized dentin (Hashimoto et al., 2002a; Pashley et al., 2011), resulting in the formation of a weaker and non-impregnated demineralized dentin zone at the bottom of these hybrid layers (Cetinguc et al., 2006; Hashimoto et al., 2000), as observed in the nanoleakage images.

A closer view at the MPA results showed that higher resin-dentin bond strength values were observed for more acidic MPA ( $\mathrm{pH} 0.5$ ) or for each MPA when applied for a longer application time. Indeed, lower bond strength values were observed when MPA was applied for $7 \mathrm{~s}$ in comparison with MPA for $30 \mathrm{~s}$. This can be attributed to the reduced demineralization when applied for short period of time, which leads to lower bond strength values.

This same rationale is applied for MPA when different pHs are compared. It was observed that MPA with the lowest pH (MPA pH 0.5) showed the highest $\mu$ TBS when compared with MPA at $\mathrm{pH} 2$. This may be explained because MPA at $\mathrm{pH} 2$ showed a greater presence of the residual mineral and less demineralized collagen due to its lower demineralization capacity, as observed in the CLSM and ATR-FTIR evaluations. This might have prevented adequate adhesive infiltration inside the demineralized dentin, producing the lowest resin-dentin $\mu$ TBS values observed.

However, the CLSM and ATR-FTIR results showed that, independent of pHs, MPA exposed less collagen than OPA and left the surface with a greater presence of mineral deposited on dentin surfaces, even when the acidic MPA ( $\mathrm{pH}$ 0.5) was applied for $30 \mathrm{~s}$, leading us to partially accept the fifth null hypothesis. In this regard, it was hypothesized that the thinner demineralized collagen layer created by MPA-etching, as with the presence of residual brushite and OCP crystallites, may have prevented the shrinkage of the collagen matrix during infiltration of comonomers, facilitating the diffusion of the adhesive within the demineralized dentin (Sauro et al., 2013; Feitosa et al., 2013) and producing resin-dentin interfaces with lower nanoleakage results when compared to OPA (Millan Cardenas et al., 2017).

Finally, in the present study, after 6-months of water storage, the bond strengths of OPA decreased significantly. In contrast, etching dentin with MPA, regardless of the $\mathrm{pH}$ and application time, produced a stable resin-dentin interface after 6 months of water storage, leading us to partially reject the third and fourth null hypotheses. These findings are aligned with reports that compared of effectiveness of MPA after 6 months (Feitosa et al., 2013).

Unfortunately, adhesive bonding with OPA showed higher amounts of nanoleakage at the immediate time. Nanoleakage reveals the location of defects at the resin-dentin interface that may serve as pathways for degradation of resin-dentin bonds over time. Silver nitrate ions occupy nanometer-sized spaces around unprotected collagen fibrils, where resin failed to infiltrate or where residual water/solvent was not displaced by the adhesive resin (Tjaderhane et al., 2013).

It worth mentioning that, when the OPA-etched dentin surface was analyzed by ATR-FTIR, the presence of brushite was not detected on the surface and the CLSM results showed that OPA exposed more fibrils that left the surface with a lower presence of mineral (OCP and brushite) deposited on dentin surfaces, leading us to partially reject the fifth null hypothesis. All of these features made the interface more susceptible to degradation after water storage, as shown by the results after 6-months of water storage when OPA was applied (Hashimoto et al., 2002b; Perdigao and Lopes, 2001; Sabatini and Pashley, 2014; Tjaderhane et al., 2013)

The better results for MPA after 6-months of water storage could be attributed to several mechanisms acting synergistically. After dentin etching, the presence of brushite was observed in groups when MPA with $\mathrm{pH} 0.5$ and $\mathrm{pH} 1$ were applied. Additionally, the CLSM results showed that, independent of pHs, MPA exposed less collagen and a greater amount of mineral (OCP and brushite) was deposited on the dentin surfaces. These differences in the demineralization rate indicates that MPA was able to promote dissolution of the smear layer on the dentin surface, providing for resin monomer diffusion and mechanical interlocking (Feitosa et al., 2013; Millan Cardenas et al., 2017), leading to higher bond strength and lower nanoleakage values for MPA, independently of application time or $\mathrm{pH}$. All of these factors could have combined to create a more stable resin-dentin interface when compared to OPA after 6-month of water storage.

Despite the positive findings reported in the present study regarding the dentin bonding durability with MPA when used in the adhesive protocol, there are some limitations: 1 ) it is still a necessity to perform in vitro studies with dentin bonding long-term follow-ups, and; 2) it is very important that randomized clinical trials are conduct to clarify whether the use of MPA-acid preserves the resin-dentin interface, before it can be discussed as a real alternative to OPA.

\section{Conclusion}

The use of $40 \%$ meta-phosphoric acid with a $\mathrm{pH}$ of 0.5 is an alternative acid-etching agent to dentin and enamel bonding, irrespective of the application time. This etchant produces high bond strength and lower nanoleakage when compared to the traditional $37 \%$ ortho phosphoric acid after 6-months of water storage, due to the presence of brushite and octacalcium phosphate, as well as a decreased demineralization pattern when compared to ortho-phosphoric acid.

\section{References}

Armstrong, S.R., Vargas, M.A., Chung, I., Pashley, D.H., Campbell, J.A., Laffoon, J.E., Qian, F., 2004. Resin-dentin interfacial ultrastructure and microtensile dentin bond strength after five-year water storage. Oper. Dent. 29, 705-712. 
Barkmeier, W.W., Erickson, R.L., Kimmes, N.S., Latta, M.A., Wilwerding, T.M., 2009 Effect of enamel etching time on roughness and bond strength. Oper. Dent. 34, 217-222.

Botelho, M.P.J., Isolan, C.P., Schwantz, J.K., Lopes, M.B., Moraes, R.R., 2017. Rubbing time and bonding performance of one-step adhesives to primary enamel and dentin. J. Appl. Oral. Sci. 25, 523-532.

Breschi, L., Mazzoni, A., Ruggeri, A., Cadenaro, M., Di Lenarda, R., De Stefano Dorigo, E., 2008. Dental adhesion review: aging and stability of the bonded interface. Dent. Mater. 24, 90-101.

Breschi, L., Prati, C., Gobbi, P., Pashley, D., Mazzotti, G., Teti, G., Perdigao, J., 2004 Immunohistochemical analysis of collagen fibrils within the hybrid layer: a FEISEM study. Oper. Dent. 29, 538-546.

Cetinguc, A., Olmez, S., Vural, N., 2006. HEMA diffusion from dentin bonding agents through various dentin thicknesses in primary molars. Am. J. Dent. 19, 231-235.

El Feninat, F., Ellis, T.H., Sacher, E., Stangel, I., 2001. A tapping mode AFM study of collapse and denaturation in dentinal collagen. Dent. Mater. 17, 284-288.

Feitosa, V.P., Bazzocchi, M.G., Putignano, A., Orsini, G., Luzi, A.L., Sinhoreti, M.A., Watson, T.F., Sauro, S., 2013. Dicalcium phosphate (CaHPO4.2H2O) precipitation through ortho- or meta-phosphoric acid-etching: effects on the durability and nanoleakage/ultra-morphology of resin-dentine interfaces. J. Dent. 41, 1068-1080.

Fujisawa, R., Kuboki, Y., 1992. Affinity of bone sialoprotein and several other bone and dentin acidic proteins to collagen fibrils. Calcif. Tissue Int. 51, 438-442.

Guba, C.J., Cochran, M.A., Swartz, M.L., 1994. The effects of varied etching time and etching solution viscosity on bond strength and enamel morphology. Oper. Dent. 19, $146-153$.

Hashimoto, M., Ohno, H., Endo, K., Kaga, M., Sano, H., Oguchi, H., 2000. The effect of hybrid layer thickness on bond strength: demineralized dentin zone of the hybrid layer. Dent. Mater. 16, 406-411.

Hashimoto, M., Ohno, H., Kaga, M., Sano, H., Endo, K., Oguchi, H., 2002a. The extent to which resin can infiltrate dentin by acetone-based adhesives. J. Dent. Res. 81, 74-78.

Hashimoto, M., Ohno, H., Kaga, M., Sano, H., Tay, F.R., Oguchi, H., Araki, Y., Kubota, M., 2002b. Over-etching effects on micro-tensile bond strength and failure patterns for two dentin bonding systems. J. Dent. 30, 99-105.

Heintze, S.D., Rousson, V., 2012. Clinical effectiveness of direct class II restorations - a meta-analysis. J. Adhes. Dent. 14, 407-431.

Kimmes, N.S., Barkmeier, W.W., Erickson, R.L., Latta, M.A., 2010. Adhesive bond strengths to enamel and dentin using recommended and extended treatment times. Oper. Dent. 35, 112-119.

Lenzi, T.L., Braga, M.M., Raggio, D.P., 2014. Shortening the etching time for etch-andrinse adhesives increases the bond stability to simulated caries-affected primary dentin. J. Adhes. Dent. 16, 235-241.

Liu, Y., Tjaderhane, L., Breschi, L., Mazzoni, A., Li, N., Mao, J., Pashley, D.H., Tay, F.R., 2011. Limitations in bonding to dentin and experimental strategies to prevent bond degradation. J. Dent. Res. 90, 953-968.

Loguercio, A.D., Munoz, M.A., Luque-Martinez, I., Hass, V., Reis, A., Perdigao, J., 2015. Does active application of universal adhesives to enamel in self-etch mode improve their performance? J. Dent. 43, 1060-1070.

Mahn, E., Rousson, V., Heintze, S., 2015. Meta-analysis of the influence of bonding parameters on the clinical outcome of tooth-colored cervical restorations. J. Adhes. Dent. 17, 391-403.

Mazzoni, A., Pashley, D.H., Nishitani, Y., Breschi, L., Mannello, F., Tjaderhane, L., Toledano, M., Pashley, E.L., Tay, F.R., 2006. Reactivation of inactivated endogenous proteolytic activities in phosphoric acid-etched dentine by etch-and-rinse adhesives. Biomaterials 27, 4470-4476.

Millan Cardenas, A.F., Figueredo de Siqueira, F.S., Bandeca, M.C., Feitosa, V.P., Reis, A., Loguercio, A.D., Gomes, J.C., 2017. Effect of $\mathrm{pH}$ and application times of a metaphosphoric acid on resin-dentin bonding properties. Int. J. Adhes. Adhes. 74, 107-114.

Muñoz, M.A., Baggio, R., Emilio Mendes, Y.B., Gomes, G.M., Luque-Martinez, I., Loguercio, A.D., Reis, A., 2014. The effect of the loading method and cross-head speed on resin-dentin microshear bond strength. Int. J. Adhes. Adhes. 50, 136-141.

Murakami, Y., Honda, Y., Anada, T., Shimauchi, H., Suzuki, O., 2010. Comparative study on bone regeneration by synthetic octacalcium phosphate with various granule sizes. Acta Biomater. 6, 1542-1548.

Nakabayashi, N., Kojima, K., Masuhara, E., 1982. The promotion of adhesion by the infiltration of monomers into tooth substrates. J. Biomed. Mater. Res. 16, 265-273.

Nishitani, Y., Yoshiyama, M., Wadgaonkar, B., Breschi, L., Mannello, F., Mazzoni, A., Carvalho, R.M., Tjaderhane, L., Tay, F.R., Pashley, D.H., 2006. Activation of gelatinolytic/collagenolytic activity in dentin by self-etching adhesives. Eur. J. Oral. Sci. $114,160-166$.

Oliver, R.G., 1987. The effects of differing etch times on the etch pattern on enamel of unerupted and erupted human teeth examined using the scanning electron microscope. Br. J. Orthod. 14, 105-107.
Osorio, R., Aguilera, F.S., Otero, P.R., Romero, M., Osorio, E., Garcia-Godoy, F., Toledano, M., 2010. Primary dentin etching time, bond strength and ultra-structure characterization of dentin surfaces. J. Dent. 38, 222-231.

Osorio, R., Yamauti, M., Osorio, E., Ruiz-Requena, M.E., Pashley, D., Tay, F., Toledano, M., 2011. Effect of dentin etching and chlorhexidine application on metalloproteinase-mediated collagen degradation. Eur. J. Oral. Sci. 119, 79-85.

Pashley, D.H., Ciucchi, B., Sano, H., Horner, J.A., 1993. Permeability of dentin to adhesive agents. Quintessence Int. 24, 618-631.

Pashley, D.H., Tay, F.R., Breschi, L., Tjaderhane, L., Carvalho, R.M., Carrilho, M., Tezvergil-Mutluay, A., 2011. State of the art etch-and-rinse adhesives. Dent. Mater. 27, $1-16$.

Perdigao, J., Geraldeli, S., Carmo, A.R., Dutra, H.R., 2002. In vivo influence of residual moisture on microtensile bond strengths of one-bottle adhesives. J. Esthet. Restor. Dent. 14, 31-38.

Perdigao, J., Lopes, M., 2001. The effect of etching time on dentin demineralization. Quintessence Int. 32, 19-26.

Profeta, A.C., Mannocci, F., Foxton, R., Watson, T.F., Feitosa, V.P., De Carlo, B., Mongiorgi, R., Valdre, G., Sauro, S., 2013. Experimental etch-and-rinse adhesives doped with bioactive calcium silicate-based micro-fillers to generate therapeutic resin-dentin interfaces. Dent. Mater. 29, 729-741.

Reis, A., Carrilho, M., Breschi, L., Loguercio, A.D., 2013. Overview of clinical alternatives to minimize the degradation of the resin-dentin bonds. Oper. Dent. 38, E1-E25.

Reis, A., de Carvalho Cardoso, P., Vieira, L.C., Baratieri, L.N., Grande, R.H., Loguercio, A.D., 2008. Effect of prolonged application times on the durability of resin-dentin bonds. Dent. Mater. 24, 639-644.

Reis, A., Grande, R.H., Oliveira, G.M., Lopes, G.C., Loguercio, A.D., 2007. A 2-year evaluation of moisture on microtensile bond strength and nanoleakage. Dent. Mater. 23, $862-870$.

Sabatini, C., Pashley, D.H., 2014. Mechanisms regulating the degradation of dentin matrices by endogenous dentin proteases and their role in dental adhesion. A review. Am. J. Dent. 27, 203-214.

Sauro, S., Osorio, R., Fulgencio, R., Watson, T.F., Cama, G., Thompson, I., Toledano, M., 2013. Remineralisation properties of innovative light-curable resin-based dental materials containing bioactive micro-fillers. J. Mater. Chem. B 1, 2624-2638.

Scaffa, P.M., Vidal, C.M., Barros, N., Gesteira, T.F., Carmona, A.K., Breschi, L., Pashley, D.H., Tjaderhane, L., Tersariol, I.L., Nascimento, F.D., Carrilho, M.R., 2012. Chlorhexidine inhibits the activity of dental cysteine cathepsins. J. Dent. Res. 91, $420-425$.

Scheffel, D.L., Ricci, H.A., de Souza Costa, C.A., Pashley, D.H., Hebling, J., 2013. Effect of reducing acid etching time on bond strength to noncarious and caries-affected primary and permanent dentin. Pediatr. Dent. 35, 199-204.

Schneider, C.A., Rasband, W.S., Eliceiri, K.W., 2012. NIH Image to ImageJ: 25 years of image analysis. Nat. Methods 9, 671-675.

Shimada, Y., Yamaguchi, S., Tagami, J., 2002. Micro-shear bond strength of dual-cured resin cement to glass ceramics. Dent. Mater. 18, 380-388.

Shimaoka, A.M., de Andrade, A.P., Cardoso, M.V., de Carvalho, R.C., 2011. The importance of adhesive area delimitation in a microshear bond strength experimental design. J. Adhes. Dent. 13, 307-314.

Skovron, L., Kogeo, D., Gordillo, L.A., Meier, M.M., Gomes, O.M., Reis, A., Loguercio, A.D., 2010. Effects of immersion time and frequency of water exchange on durability of etch-and-rinse adhesive. J. Biomed. Mater. Res. B Appl. Biomater. 95, 339-346.

Tay, F.R., Pashley, D.H., Suh, B.I., Carvalho, R.M., Itthagarun, A., 2002. Single-step adhesives are permeable membranes. J. Dent. 30, 371-382.

Tjaderhane, L., Nascimento, F.D., Breschi, L., Mazzoni, A., Tersariol, I.L., Geraldeli, S., Tezvergil-Mutluay, A., Carrilho, M., Carvalho, R.M., Tay, F.R., Pashley, D.H., 2013. Strategies to prevent hydrolytic degradation of the hybrid layer-A review. Dent. Mater. 29, 999-1011.

Tsujimoto, A., Barkmeier, W.W., Takamizawa, T., Latta, M.A., Miyazaki, M., 2016a. The effect of phosphoric acid pre-etching times on bonding performance and surface free energy with single-step self-etch adhesives. Oper. Dent. 41, 441-449.

Tsujimoto, A., Barkmeier, W.W., Takamizawa, T., Watanabe, H., Johnson, W.W., Latta, M.A., Miyazaki, M., 2016b. Influence of duration of phosphoric acid pre-etching on bond durability of universal adhesives and surface free-energy characteristics of enamel. Eur. J. Oral. Sci. 124, 377-386.

Tsujimoto, A., Fischer, N., Barkmeier, W., Baruth, A., Takamizawa, T., Latta, M., Miyazaki, M., 2017. Effect of reduced phosphoric acid pre-etching times on enamel surface characteristics and shear fatigue strength using universal adhesives. J. Adhes. Dent. 19, 267-275.

Van Meerbeek, B., Dhem, A., Goret-Nicaise, M., Braem, M., Lambrechts, P., VanHerle, G., 1993. Comparative SEM and TEM examination of the ultrastructure of the resindentin interdiffusion zone. J. Dent. Res. 72, 495-501.

Wang, Y., Spencer, P., 2002. Quantifying adhesive penetration in adhesive/dentin interface using confocal Raman microspectroscopy. J. Biomed. Mater. Res. 59, 46-55. 